\title{
Long term trends in abundance of humpback whales in Hervey Bay, Australia
}

\author{
Paul H. Forestell*, ${ }^{*}$, Gregory D. Kaufman* and Milani Chaloupka ${ }^{\#}$ \\ Contacte-mail: paul.forestell@liu.edu
}

\begin{abstract}
Seasonal abundance estimates of humpback whales resident during the austral winter in Hervey Bay, Queensland, Australia between 1987 and 2007 were obtained from a capture-mark-recapture study using photo-identification images of 3,155 individual whales. Hervey Bay is a major southbound stopover site for Breeding Stock E humpback whales returning to Antarctic waters from over-wintering in the vicinity of the Great Barrier Reef. Annual survival, recapture and abundance estimates were derived using a Cormack-Jolly-Seber modelling approach and a Horwitz-Thompson type abundance estimator. The best-fit model was a 2-ageclass Brownie-Robson type model that estimated apparent annual survival for the non-transient winter stopover ageclass at approximately 0.945 (95\% confidence interval: 0.929-0.957). Apparent annual abundance of winter stopover humpback whales in Hervey Bay was estimated to have increased significantly over the past 21 years at $c a$. 13.4\% per annum (95\% CI 11.6-15.2). The most recent Hervey Bay winter stopover population (2007) was estimated to comprise ca. 6,246 post-yearlings (95\% CI 5,011-7,482). This estimated rate of population increase is similar to estimates for other surveys along the east Australian coast but significantly higher than the intrinsic rate of increase ( $\max$ ) estimated recently for several recovering Southern Hemisphere humpback whale stocks based on the feeding ground sampling.
\end{abstract}

KEYWORDS: HUMPBACK WHALE; ABUNDANCE ESTIMATE; MARK-RECAPTURE; PHOTO-ID; AUSTRALIA; SOUTHERN HEMISPHERE; STATISTICS

\section{INTRODUCTION}

Humpback whales that migrate along the east coast of Australia are part of the Southern Hemisphere Breeding Stock E, which spend the austral summer in Antarctic Area $\mathrm{V}\left(130^{\circ} \mathrm{E}-170^{\circ} \mathrm{W}\right)$, and the austral winter breeding and calving in tropical waters in the vicinity of the Great Barrier Reef (Chittleborough, 1965; Dawbin, 1966; Kaufman et al., 1990). Like stocks of humpback whales in other parts of the world, East Australia humpback whales were severely depleted by commercial whaling. By 1962, the entire Stock E was estimated to be between 200 and 500 animals (Allen, 1980; Chittleborough, 1965). The original 'pre-exploitation' population has traditionally been estimated at 10,000 (Chapman, 1974; Chittleborough, 1965), although doubt has been cast on the reliability of such estimates and subsequent population trend estimates by the revelation that the Soviets took some 40,000 unreported humpback whales in the Southern Hemisphere 1957-68 (Mikhalev, 2000). Nonetheless, since their protection from commercial whaling in 1963, there has been evidence that the number of humpback whales migrating along the east coast of Australia are increasing at a substantial annual rate, based on shorebased observations in Southern Queensland waters (Bryden et al., 1990; Noad et al., 2011; Paterson et al., 2001), aerial surveys of the Great Barrier Reef Marine Park (Chaloupka and Osmond, 1998), and analysis of photo-identification data (Chaloupka et al., 1999; Forestell et al., 2003).

Despite favourable evidence of a general increase in the number of humpback whales observed along the east coast of Australia following cessation of commercial whaling, more detailed analyses of annual changes in estimated abundance remain important for assessing the extent to which those changes represent a real increase to the overall breeding stock size (or overall population of Southern Hemisphere humpback whales), and the extent to which observed changes represent seasonal increases associated with temporary movement of whales between breeding stocks (e.g. between Breeding Stock D and E; Chittleborough, 1965) or within the sub-groups of a given breeding stock (e.g. between east coast Australia and areas throughout Oceania; Garrigue et al., 2000). As the number of potential impacts of human-generated activities and long term global cycles on marine mammal species becomes increasingly lengthy (Burns and Wandesford-Smith, 2002; Chaloupka et al., 1999; Clapham et al., 1999; Dawbin and Gill, 1991; Reeves and Reijnders, 2002; Stachowitsch et al., 2005), the need to incorporate likely effects of those impacts on long term changes in abundance becomes increasingly apparent.

The east coast of Australia is an important area for studying humpback whales. It is relatively accessible along much of its length, and it lies along a major portion of the migratory route of Breeding Stock E humpback whales (Chaloupka and Osmond, 1998; Chittleborough, 1965; Dawbin, 1966). Shore-based and aerial observations near North Stradbroke Island indicate that most humpback whales migrating along the east coast of Australia move within $10 \mathrm{~km}$ of shore (Bryden, 1985). During their southward migration towards the end of the austral winter, large numbers of humpback whales may be reliably observed in the protected waters of Hervey Bay, Queensland (approximately $25^{\circ} \mathrm{S}, 153^{\circ} \mathrm{E}$ ), especially in Platypus Bay, along the northwestern shores of Fraser Island (Forestell et al., 2003; Kaufman et al., 1987). The data reported here are derived from a long term photo-identification-based capturemark-recapture programme that commenced in Hervey Bay in 1987.

\footnotetext{
* Pacific Whale Foundation, Wailuku, Hawaii 97653, USA.

C.W. Post Campus of Long Island University, Brookville, NY 11548, USA.

\# Ecological Modelling Services Pty Ltd, University of Queensland, St Lucia, Queensland 4067, Australia.
} 


\section{MATERIALS AND METHODS}

\section{Study area and dataset}

The study was conducted in the Hervey Bay Marine Park that comprises around $1,600 \mathrm{~km}^{2}$ in area (Chaloupka et al., 1999). Hervey Bay is a large, shallow embayment on the east coast of Australia $\left(25^{\circ} 00^{\prime} \mathrm{S}, 152^{\circ} 52^{\prime} \mathrm{E}\right)$ and is the major southbound stopover site for humpback whales returning to Antarctic waters from overwintering in the Great Barrier Reef (Chaloupka et al., 1999). Boat-based observations were conducted on a daily basis during each field season, depending upon weather conditions, using a small (5-6m) inflatable vessel equipped with outboard motors. During each sampling day the survey team would opportunistically search for pods of humpback whales throughout the marine park area of the Bay. Radio communication with whalewatch boats in the area was also used on occasion to help locate pods. Photographs of the ventral surface of the tail flukes were obtained using $35 \mathrm{~mm}$ film or digital cameras equipped with motor drives and 300mm lenses (Kaufman et al., 1987). Date, time, location, sea state, wind speed, direction and degree of cloud cover, sea surface temperature, pod number, pod composition and image number and content of each photograph were recorded. Photographs were processed using previously described techniques (Forestell et al., 2003; Kaufman et al., 1993) and then used to create a photo-identification-based recapture history for each humpback whale encountered in the sampling area over the 21 year period from 1987 to 2007.

\section{Statistical methods}

The Cormack-Jolly-Seber (CJS) modelling approach (Lebreton et al., 1992) was used to estimate recapture and survival probabilities from the 2,142 recapture histories. All models were fitted using MARK (White et al., 2006) while model selection was based on the quasi-likelihood form of Akaike Information Criterion, which is corrected for sample size and possible overdispersion (QAICc; Anderson et al., 1998). CJS model assumptions were evaluated using RELEASE and UCARE (Pradel et al., 2005) while goodnessof-fit was assessed using a bootstrap approach implemented in MARK. The best-fit model was used to estimate recapture and survival probability estimates. Annual sampling effort measured as either boat-days or boat-hours was fairly constant in the study area over the 21 year period except for 2001 and 2003, when there was little or no sampling effort. Therefore, the recapture parameters for these two sampling occasions were fixed to zero in the model estimation. The best-fit model capture probabilities (and variance estimates) were then used to derive annual Horwitz-Thompson type abundance estimates $\left(N_{i}=\left(n_{i} / \rho_{i}\right)\right)$ (McDonald and Amstrup, 2001) of the humpback whale population in the Hervey Bay sampling area between 1987 and 2007, where $n_{i}$ is number of whales captured in the $i$ th year, $N_{i}$ is number of whales in the sampled population in the $i$ th year and $\rho_{i}$ is estimated recapture probability in the $i$ th year. The appropriate variance formulae for this estimator are provided in detail by McDonald and Amstrup (2001). The expected population growth rate was derived using a generalised least squares regression of the $\mathrm{CV}^{2}$-weighted annual abundance estimates with first order moving average (MA1) error structure, which was fitted using the nlme package in $R$ (Pinheiro and Bates, 2000).

\section{RESULTS}

The dataset comprised the recapture histories for 3,155 individual post-yearling humpback whales sampled over the 21 year period from 1987 to 2007 . The mark-resight summary statistics for the 3,155 resight profiles are shown in Table 1. Calves were not included in this study because they rarely expose the ventral surface of their flukes needed for photo-identification (Kaufman et al., 1993) and there can be significant change in pigmentation patterning during the first year of postnatal development (Carlson et al., 1990). Sex was not considered because few whales in the sample could be sexed reliably and also because younger males are more likely to be sexed than adult males due to frequent rollover behaviour (Chaloupka et al., 1999).

All CJS models fitted are summarised in Table 2. The reference or global model was the fully time-dependent model shown as model 3 in Table 2. Several other CJS models were also fitted to compare with the global model (models 2,4,5: Table 2). The adequacy of the global model was assessed using variants of TESTS 2 and 3 in RELEASE and UCARE (Pradel et al., 2005), which indicated failure only of test component $3 . \mathrm{SR}\left(\chi^{2}=120.37, \mathrm{df}=17, p<0.001\right)$ but not Test 2.CT or Test 3.SM. Failure of test component 3.SR is considered to be a consequence of the transient behaviour of individuals that were just passing through the study area and were not seen again (Pradel et al., 2005). Consequently, we also fitted a simple age-specific survival model to account for apparent transient behaviour by separating into two ageclasses: newly marked; and previously marked whales. Ageclass is used here for convenience to refer to two groups that are based on timesince-first-marking, which is a form of quasi ageing although age is not strictly known. The two ageclasses might reflect differences in site fidelity between neophyte migrants and experienced migrants on the southbound migration back to Antarctic feeding grounds. The best-fit model of all the five models fitted was the 2-ageclass-specific Brownie-Robson type model (model 1 in Table 2) and a simple bootstrap goodness-of-fit assessment suggested an adequate model fit overall $(p=0.47)$.

The estimated annual survival probability derived from model 1 (Table 2) for the newly marked ageclass or 'transients' in the Brownie-Robson model was 0.631 (95\% CI 0.576-0.682). Estimated annual apparent survival probability for the previously marked ageclass in the Brownie-Robson model was 0.945 (95\% CI 0.929-0.956). The transients might be younger (neophyte migrant) whales with lower survival probability or whales just rapidly moving through the study area and never seen again, which in the latter case would strongly confound survival and permanent emigration. The survival estimate for the previously marked (and perhaps older and experienced migrants) whales is significantly higher than the estimate for the newly marked whales and is presumably far less biased by any permanent emigration effect. The survival estimate for the previously marked humpback whales is also consistent with the expected annual survival probability of highly mobile, longlived, later maturing marine species such as bowhead whales (Zeh et al., 2002), right whales (Caswell et al., 1999), sea turtles (Troeng and Chaloupka, 2007) and manatees (Langtimm et al., 1998).

The estimated annual recapture probabilities derived from the best-fit model were time-dependent and ranged from $0.04-0.43$ with a geometric mean $c a$. 0.13 . These recapture estimates derived from model 1 (Table 2) were then used to derive the Horwitz-Thompson type estimates of humpback whale abundance in the sampling area that are shown in Fig. 1a. The expected annual population growth rate trend in these annual abundance estimates is shown in Fig. 1b and was estimated to be $c a$. $13.4 \%$ per annum (95\% CI $11.6-$ 
Table 1

Mark-resight summary statistics for humpbacks resident in the Hervey Bay Marine Park sampling area during the annual southward migration (1987 to 2007). Summary notation as follows: $n_{i}=$ total number of humpbacks (marked + unmarked) sighted in $i$ th period, $m_{i}=$ number of marked humpbacks sighted in $i$ th period, $R_{i}=$ number of $n$ released after $i$ th period, $r_{i}=$ number of $R_{i}$ sighted in $i$ th period and resighted in a subsequent period, $z_{i}=$ number sighted before and after $i$ th period but not in $i$ th period, effort $=$ total sampling effort in boat-days in $i$ th period.

\begin{tabular}{|c|c|c|c|c|c|c|c|}
\hline Period & Year & $n_{i}$ & $m_{i}$ & $R_{i}$ & $r_{i}$ & $z_{i}$ & Effort $_{i}$ \\
\hline 1 & 1987 & 30 & 0 & 30 & 19 & & 27 \\
\hline 2 & 1988 & 179 & 9 & 179 & 106 & 10 & 59 \\
\hline 3 & 1989 & 159 & 42 & 159 & 86 & 74 & 30 \\
\hline 4 & 1990 & 105 & 31 & 105 & 48 & 129 & 30 \\
\hline 5 & 1991 & 129 & 36 & 129 & 63 & 141 & 31 \\
\hline 6 & 1992 & 119 & 39 & 119 & 58 & 165 & 37 \\
\hline 7 & 1993 & 212 & 68 & 212 & 100 & 155 & 48 \\
\hline 8 & 1994 & 172 & 81 & 172 & 78 & 174 & 57 \\
\hline 9 & 1995 & 89 & 43 & 89 & 32 & 209 & 16 \\
\hline 10 & 1996 & 126 & 50 & 126 & 49 & 191 & 22 \\
\hline 11 & 1997 & 161 & 44 & 161 & 55 & 196 & 30 \\
\hline 12 & 1998 & 236 & 79 & 236 & 66 & 172 & 31 \\
\hline 13 & 1999 & 189 & 60 & 189 & 46 & 178 & 35 \\
\hline 14 & 2000 & 219 & 64 & 219 & 45 & 160 & 44 \\
\hline 15 & 2001 & 0 & 0 & 0 & 0 & 205 & 0 \\
\hline 16 & 2002 & 174 & 51 & 174 & 46 & 154 & 49 \\
\hline 17 & 2003 & 0 & 0 & 0 & 0 & 200 & 0 \\
\hline 18 & 2004 & 235 & 30 & 235 & 45 & 170 & 53 \\
\hline 19 & 2005 & 453 & 97 & 453 & 66 & 118 & 59 \\
\hline 20 & 2006 & 587 & 118 & 587 & 54 & 66 & 56 \\
\hline 21 & 2007 & 643 & 120 & 643 & & & 62 \\
\hline
\end{tabular}

15.2). The highest winter stopover abundance estimate derived from this study to date was in 2007 (Fig. 1a) at $c a$. 6,246 post-yearling humpbacks (95\% CI 5,011-7,482).

\section{DISCUSSION}

The Hervey Bay study area has shown a marked increase in the estimated number of humpback whales visiting there over the 21 years of this study. Fig. 1a demonstrates the increase was relatively minimal from $1987-95$, moderate through to 2000, and remarkably high since then. This would explain the difference between the overall trend reported here up to 2005, and the earlier findings of Chaloupka et al. (1999), based on 10 years of Pacific Whale Foundation photo-identification data from Hervey Bay (1987-1996) and four years from the Whitsunday Islands, Queensland; and Forestell et al. (2003), based on a seven-year analysis of resights and exchange rates between Hervey Bay and the Whitsunday Islands. Those estimates suggested considerably lower overall rates of change in abundance, but they were

Table 2

Summary of model fits.

$\varphi=$ survival probability, $\rho=$ recapture probability, $()=$. constant,$(t)=$ timedependent, $a 2$ = Brownie-Robson 2-ageclass structure to account for apparent transience, QAICc $=$ sample size and overdispersion corrected Akaike Information Criterion, Pars $=$ number of model parameters. Overdispersion parameter used to adjust AICc c-hat $=1.19$.

\begin{tabular}{ccccccc}
\hline \multirow{2}{*}{ Model } & Description & QAICc & $\Delta$ QAICc & $\begin{array}{c}\text { Model } \\
\text { likelihood }\end{array}$ & Pars & Deviance \\
\hline 1 & $\varphi(\mathrm{a} 2) \rho(t)$ & $6,465.93$ & 0.00 & 1.000 & 20 & $1,451.30$ \\
2 & $\varphi(.) \rho(t)$ & $6,525.62$ & 59.69 & 0.000 & 19 & $1,513.01$ \\
3 & $\varphi(t) \rho(t)$ & $6,541.55$ & 75.61 & 0.000 & 32 & $1,502.55$ \\
4 & $\varphi(t) \rho()$. & $6,777.36$ & 311.42 & 0.000 & 10 & $1,782.89$ \\
5 & $\varphi(.) \rho()$. & $6,865.96$ & 400.03 & 0.000 & 2 & $1,887.56$ \\
\hline
\end{tabular}
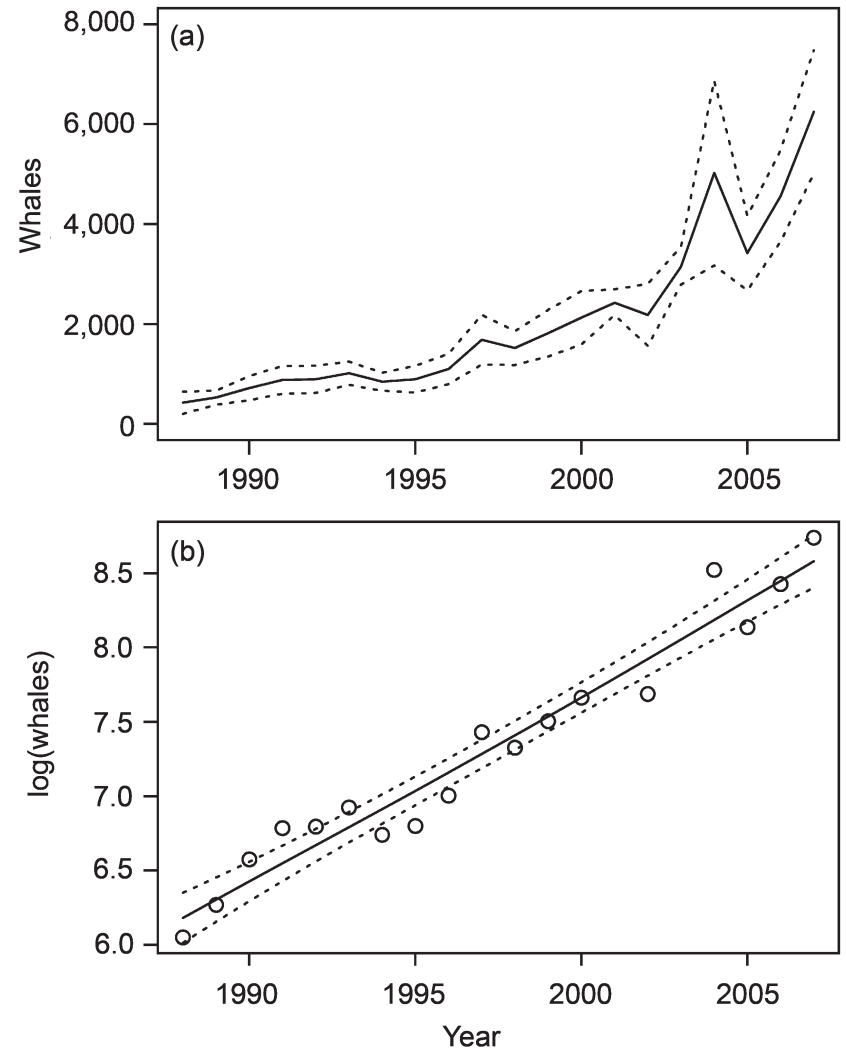

Fig. 1. Panel (a) shows Horwitz-Thompson annual abundance estimates (solid curve) and 95\% confidence curves (dotted curves). Panel (b) shows on a log scale the Horwitz-Thompson annual abundance estimates (open dots) with the linear trend (solid curve) estimated by a linear regression model with MA(1) and 95\% confidence bands (dotted lines) - model fitted using nlme package in $R$.

based primarily on time periods prior to the onset of the rapid increases in more recent years demonstrated in the current findings. The overall increase in abundance estimates reported here is consistent with reports of increases in the number of humpback whales migrating along the east Australian coastline reported by others (Noad et al., 2011; Paterson et al., 2001), derived from shore-based counts of animals moving past North Stradbroke Island early in the season, during the northward phase of the annual migration.

Branch (2011) provides estimates of humpback whale abundance and rates of change based on three circumpolar surveys of Antarctic waters during the austral summer across the years 1978-2004. He reported a circumpolar annual rate of increase of $9.6 \%$ (95\% CI 5.8-13.4), near the theoretical limit for humpback whales (Clapham et al., 2006). Branch (2011) estimates annual rate of increase for Breeding Stock $\mathrm{E}$ at $14.4 \%$ (95\% CI 9.6-19.2), similar to the Hervey Bay findings reported here. However, it is highly unlikely that the intrinsic rate of increase (rmax) for Breeding Stock E humpback whales could be so high (Clapham et al., 2006). Branch (2011) notes that the small number of abundance estimates, high associated CVs, changes in survey design, and annual changes in humpback whale distribution severely limit the accuracy of the rate of change estimates for individual areas (stocks).

It is unlikely that the long term increase found for the Hervey Bay stopover population reflects the intrinsic rate of increase for Breeding Stock E humpback whales. The various estimated rates of increase of the population segment of the east Australian stock that migrates each year along the east Australia coast are all significantly higher than the 
intrinsic rate of increase ( $\max$ ) estimated recently for various recovering Southern Hemisphere humpback whale stocks based on the feeding ground sampling (Johnston and Butterworth, 2006).

The humpback whales entering Hervey Bay were found to comprise two major ageclasses that demonstrate significantly different survival rates: those captured once and not seen again (transients); and those re-captured following initial sighting. The transient portion of the Hervey Bay animals could represent a range of possibilities that reflect important demographic differences in lower ageclassspecific mortality, or ageclass-specific dispersal behaviour. A measure of transient behaviour that reflects temporary shifts in distribution between breeding stocks or between areas within breeding stocks would be important for improving the accuracy of stock assessment and estimates of change in abundance, particularly in light of recent estimates of population abundance and rate of increase that do not consider the effect of transients over extended time periods (Noad et al., 2008; Noad et al., 2011; Paterson et al., 2001; Paton et al., 2006). More accurate measures require the use of multi-state models (Pradel et al., 2005). While there have been limited efforts to undertake such an analysis (Forestell et al., 2003; Paton et al., 2006), there is a pressing need to complete a comprehensive comparison of all available photo-identification images for this stock of whales.

Finally, it should be noted that whatever evidence there may be that whales behave differently in the presence or absence of whalewatching boats in Hervey Bay (Corkeron, 1995), these differences appear not to have had a deleterious long term effect on the number of whales that visit the area annually.

\section{ACKNOWLEDGEMENTS}

This work was made possible by the members and supporters of the Pacific Whale Foundation. Additional funding was obtained from the Queensland Department of the Environment, Parks and Wildlife Service and Matilda Cruises. We thank Dave Perkins, Tim Smith and Alan Jeffrey for encouragement and early support of this work. The cooperation of the captains and crews of the Hervey Bay whalewatch fleet are much appreciated. All work was conducted under permit from the Queensland government. We thank the Maryborough office of QNPWS/EPA for their assistance.

\section{REFERENCES}

Allen, K.R. 1980. Conservation and Management of Whales. University of Washington Press, Seattle and Butterworth and Co., London. ix $+110 \mathrm{pp}$. Anderson, D.R., Burnham, K.P. and White, G.C. 1998. Comparison of Akaike Information Criterion and consistent Akaike Information Criterion for model selection and statistical inference from capturerecapture studies. Journal of Applied Statistics 25: 263-82.

Branch, T.A. 2011. Humpback abundance south of $60^{\circ} \mathrm{S}$ from three complete circumpolar sets of surveys. J. Cetacean Res. Manage. (special issue 3): 53-69.

Bryden, M.M. 1985. Studies of humpback whales (Megaptera novaeangliae), Area V. pp.115-23. In: Ling, J.K. and Bryden, M.M. (eds). Studies of Sea Mammals in South Latitudes. South Australian Museum, Adelaide.

Bryden, M.M., Kirkwood, G.P. and Slade, R.W. 1990. Humpback whales, Area V. An increase in numbers off Australia's east coast. pp.261-77. In: Kerry, K.R. and Hempel, G. (eds). Antarctic Ecosystems. Ecological Change and Conservation. Springer-Verlag, Berlin, Heidelberg. 327pp.

Burns, W.G.G. and Wandesford-Smith, G. 2002. The 53rd meeting of the International Whaling Commission and the future of cetaceans in a changing world. Rev. Europ. Commun. and Intl. Env. Law 11: 199-210.
Carlson, C.A., Mayo, C.A. and Whitehead, H. 1990. Changes in the ventral fluke pattern of the humpback whale (Megaptera novaeangliae), and its effects on matching; evaluation of its significance to photo-identification research. Rep. int. Whal. Commn (special issue) 12: 105-11.

Caswell, H., Fujiwara, M. and Brault, S. 1999. Declining survival probability threatens the North Atlantic right whale. Proc. Natl Acad. Sci. USA 96(6): 3,308-13.

Chaloupka, M. and Osmond, M. 1998. Spatial and seasonal distribution of humpback whales in the Great Barrier Reef. pp.89-106. In: Musick, J.A. (eds). Life in the Slow Lane: Ecology and Conservation of Long-lived Marine Mammals. Am. Fish. Soc. Symp.

Chaloupka, M., Osmond, M. and Kaufman, G. 1999. Estimating seasonal abundance and survival rates of humpback whales in Hervey Bay (east coast Australia). Mar. Ecol. Prog. Ser. 184: 291-301.

Chapman, D.G. 1974. Status of the Antarctic rorqual stocks. pp.218-38. In: Schevill, W.E. (eds). The Whale Problem, A Status Report. Harvard University Press, Massachusetts. $\mathrm{x}+419 \mathrm{pp}$.

Chittleborough, R.G. 1965. Dynamics of two populations of the humpback whale, Megaptera novaeangliae (Borowski). Aust. J. Mar. Freshwater Res. 16(1): 33-128.

Clapham, P., Wade, P. and Zerbini, A. 2006. Plausible rates of population growth in humpback whales revisited. Paper SC/58/SH4 presented to the IWC Scientific Committee, May 2006, St. Kitts and Nevis, West Indies (unpublished). 12pp. [Paper available from the Office of this Journal].

Clapham, P.J., Young, S.B. and Brownell, R.L., Jr. 1999. Baleen whales: conservation issues and the status of the most endangered populations. Mammal Rev. 29(1): 35-60.

Corkeron, P.J. 1995. Humpback whales (Megaptera novaeangliae) in Hervey Bay, Queensland: Behaviour and responses to whale-watching vessels. Can. J. Zool. 73(7): 1,290-1,99.

Dawbin, W.H. 1966. The seasonal migratory cycle of humpback whales. pp.145-70. In: Norris, K.S. (eds). Whales, Dolphins, and Porpoises. University of California Press, Berkeley and Los Angeles. xv+789pp.

Dawbin, W.H. and Gill, P.C. 1991. Humpback whale survey along the west coast of Australia: a comparison of visual and acoustic observations. Mem. Queensl. Mus. 30(2): 255-57.

Forestell, P.H., Kaufman, G. and Chaloupka, M. 2003. Migratory characteristics of humpback whales (Megaptera novaeangliae) in Hervey Bay and the Whitsunday Islands, Queensland, Australia: 1993-1999. Final report to the Environmental Protection Agency, Queensland Parks and Wildlife Service Brisbane, Australia, October 2003. Brisbane, Australia.

Garrigue, C., Forestell, P., Greaves, J., Gill, P., Naessig, P. and Baker, C.S. 2000. Migratory movement of humpback whales (Megaptera novaeangliae) between New Caledonia, East Australia and New Zealand. J. Cetacean Res. Manage. 2(2): 101-10.

Johnston, S.J. and Butterworth, D.S. 2006. Updated assessments of various breeding populations of Southern Hemisphere humpback whales. Paper SC/A06/HW22 presented to the IWC Workshop on Comprehensive Assessment of Southern Hemisphere Humpback Whales, Hobart, Tasmania, 3-7 April 2006 (unpublished). 38pp. [Paper available from the Office of this Journal].

Kaufman, G.D., Lagerquist, B.A., Forestell, P.H. and Osmond, M.G. 1993. Humpback Whales of Australia: a Catalogue of Individual Whales Identified by Fluke Photographs. 1st ed. Queensland Department of Environment and Heritage, Brisbane, Queensland, Australia. 207pp.

Kaufman, G.D., Osmond, M.G., Ward, A.J. and Forestell, P.H. 1990. Photographic documentation of the migratory movement of a humpback whale (Megaptera novaeangliae) between East Australia and Antarctic Area V. Rep. int. Whal. Commn (special issue) 12: 265-67.

Kaufman, G.D., Smultea, M.A. and Forestell, P.H. 1987. Use of lateral body pigmentation patterns for photographic identification of East Australian (Area V) humpback whales. Cetus 7: 5-13.

Langtimm, C.A., O'Shea, T.J., Pradel, R. and Beck, C.A. 1998. Estimates of annual survival probabilities for adult Florida manatees (Trichechus manatus latirostris). Ecology 79: 981-97.

Lebreton, J.D., Burnham, K.P., Clobert, J. and Anderson, D.R. 1992. Modeling survival and testing biological hypotheses using marked animals: a unified approach with case studies. Ecol. Monogr. 62(1): 67118 .

McDonald, T.L. and Amstrup, S.C. 2001. Estimation of population size using open capture-recapture models. J. Agr. Biol. Environ. Statistics 6: 206-20.

Mikhalev, Y.A. 2000. Biological characteristics of humpbacks taken in Antarctic Area V by the whaling fleets Slava and Sovietskaya Ukraina. Paper SC/52/IA12 presented to the IWC Scientific Committee, June 2000, Adelaide, Australia (unpublished). 18pp. [Paper available from the Office of this Journal].

Noad, M.J., Dunlop, R.A., Paton, D. and Cato, D.H. 2008. An update of the east Australian humpback whale population (E1) rate of increase. Paper 
SC/60/SH31 presented to the IWC Scientific Committee, June 2008, Santiago, Chile (unpublished). 13pp. [Paper available from the Office of this Journal].

Noad, M.J., Dunlop, R.A., Paton, D. and Cato, D.H. 2011. Absolute and relative abundance estimates of Australian east coast humpback whales (Megaptera novaeangliae). J. Cetacean Res. Manage. (special issue 3): 243-252.

Paterson, R., Paterson, P. and Cato, D.H. 2001. Status of humpback whales (Megaptera novaeangliae) in east Australia at the end of the 20th Century. Mem. Queensl. Mus. 47(2): 579-86.

Paton, D.A., Brookes, L., Burns, D., Franklin, T., Franklin, W., Harrison, P. and Baverstock, P. 2006. First abundance estimate of east coast Australian humpback whales (Megaptera novaeangliae) utilising mark-recapture analysis and multi-point sampling. Paper SC/A06/HW32 presented to the IWC Workshop on Comprehensive Assessment of Southern Hemisphere Humpback Whales, Hobart, Tasmania, 3-7 April 2006 (unpublished). $11 \mathrm{pp}$. [Paper available from the Office of this Journal].

Pinheiro, J.C. and Bates, D.M. 2000. Mixed effects models in S and S-PLUS. Springer-Verlag, New York.
Pradel, R., Gimenez, O. and Lebreton, J.D. 2005. Principles and interest of GOF tests for multistate capture-recapture models. Animal Biodiversity Conserv. 28: 189-204.

Reeves, R.R. and Reijnders, P.J.H. 2002. Conservation and management pp.388-432. In: Hoelzel, A.R. (eds). Marine Mammal Biology, An Evolutionary Approach. Blackwell Publishing, Malden, USA.

Stachowitsch, M., Parsons, E.C.M. and Rose, N.A. 2005. Report of the Scientific Committee. Annex K. Report of the Standing Working Group on Environmental Concerns. Appendix 5. State of the Cetacean Environment Report (SOCER) 2004. J. Cetacean Res. Manage. (Suppl.) 7: 290-301.

Troeng, S. and Chaloupka, M. 2007. Variation in adult annual survival probability and remigration intervals of sea turtles. Mar. Biol. 151: 1,7211,30 .

White, G.C., Kendall, W.L. and Barker, R.J. 2006. Multistate survival models and their extension in Program MARK. J. Wildl. Manage. 70: $1,521-1,29$.

Zeh, J., Poole, D., Miller, G., Koski, W., Baraff, L. and Rugh, D. 2002. Survival of bowhead whales, Balaena mysticetus, estimated from 198198 photo-identification data. Biometrics 58: 832-40. 